\title{
Pictorial blood loss assessment chart for quantification of menstrual blood loss: a systematic review
}

\author{
Sherif A. El-Nashar ${ }^{1,2} \cdot$ Sherif A. M. Shazly ${ }^{1,2}$ • Abimbola O. Famuyide ${ }^{1}$
}

Received: 9 February 2015 /Accepted: 22 April 2015 /Published online: 6 May 2015

(C) Springer-Verlag Berlin Heidelberg 2015

\begin{abstract}
To evaluate the diagnostic accuracy of pictorial blood loss assessment chart (PBLAC) compared to objective measurements of menstrual blood loss (MBL), a systematic search of MEDLINE, EMBASE, Cumulative Index to Nursing \& Allied Health Literature (CINAHL), Web of Science, and EBM Reviews-Cochrane Central Register of Controlled Trials from inception until September 30, 2014 was performed. Terms referring to "pictorial blood loss assessment chart," "menstrual blood loss evaluation," and "alkaline hematin" were used. The ability of PBLAC to predict significant blood loss, compared to alkaline hematin as a standard objective method, represents our primary outcome. Out of 255 reports identified by the primary search, seven reports were included in the review. Quality of these reports was assessed. Compared to alkaline hematin, PBLAC sensitivity and specificity ranged from 58 to $98 \%$ and 7.5 to $97 \%$, respectively, with likelihood ratios (LR) for positive ranging from 1.1 to 7.8 and LR for negative tests ranging from 0.04 to 0.48 . Diagnostic odds ratio ranged from 2.6 to 86.9. Although diagnostic testing was not always supportive in terms of sensitivity, specificity, and LRs, most studies support the use of PBLAC as a
\end{abstract}

This manuscript was presented in the Thirty-Eighth Annual Society of Gynecological Surgeon (SGS) Meeting on April 13-15, 2012, Baltimore, Maryland.

Sherif A. M. Shazly

sherify2k2@gmail.com

1 Department of Obstetrics and Gynecology, Mayo Clinic, Rochester, MN, USA

2 Department of Obstetrics and Gynecology, Assiut University, Assiut, Egypt semi-objective method that can be implemented in research and clinical practice.

Keywords Menstruation $\cdot$ Menorrhagia $\cdot$ Heavy menstrual bleeding $\cdot$ Pictorial chart · Diagnostic accuracy $\cdot$ Systematic review

\section{Background}

Evaluation of menstrual blood loss (MBL) has evoked an insisting debate for gynecologic researchers and clinicians since the early twentieth century. One of the first reports dates back to 1904, when Hoppe-Seyler and colleagues reported on the use of acid hematin in quantifying MBL [1]. In 1936, Barer and Fowler from the University of Iowa reported the results of assessment of MBL in 100 women and performed a review of the literature in which they identified 32 publications reporting on the previously proposed amount for "normal" MBL [2]. Despite this early interest, to date, there is no tool in current clinical practice that is easy to use, has good correlation with patient complaint, and can detect change in menstruation after treatment [3].

The pictorial blood assessment chart (PBLAC) is a semi-quantitative method for evaluation of MBL that was first published by Higham and Shaw in 1990 and improved and validated by Janssen and colleagues in 1995 [4-6] (Fig. 1). Recently, PBLAC has been increasingly used in clinical research especially pivotal trials that evaluated the effectiveness of non-hysteroscopicdependent endometrial ablation devices [7]. Nonetheless, there is conflicting evidence about its accuracy $[4,5$, $8-12]$. The objective of this systematic review is to 


\section{Pictorial Blood Loss Assessment Chart}

\begin{tabular}{|c|c|c|c|c|c|c|c|c|c|c|c|c|c|}
\hline DAY & DAY1 & DAY2 & DAY3 & DAY4 & DAY5 & DAY6 & DAY7 & DAY8 & DAY9 & DAY10 & \begin{tabular}{|l} 
TOTAL \\
TALLIES
\end{tabular} & $\begin{array}{l}\text { MULTIPLYING } \\
\text { FACTOR }\end{array}$ & ROW TOTAL \\
\hline- & & & & & & & & & & & & $\mathbf{x} 1$ & \\
\hline 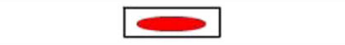 & & & & & & & & & & & & $\mathbf{x} 5$ & \\
\hline 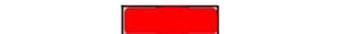 & & & & & & & & & & & & $\mathbf{x} 20$ & \\
\hline$\infty$ & & & & & & & & & & & & $\mathbf{x} 1$ & \\
\hline$\rightarrow$ - & & & & & & & & & & & & $\mathbf{X 5}$ & \\
\hline 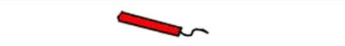 & & & & & & & & & & & & $\mathrm{x} 10$ & \\
\hline Small blood clots (= Dime) & & & & & & & & & & & & $\mathbf{x} 1$ & \\
\hline Large blood clots ( $\geq$ Quarter) & & & & & & & & & & & & $\mathbf{x} 5$ & \\
\hline Menstrual accidents & & & & & & & & & & & & $\mathrm{x} 5$ & \\
\hline \multicolumn{13}{|c|}{ Total Score (Sum of rows) } & \\
\hline
\end{tabular}

How to use the Pictorial Blood Assessment Chart:

Record the number of tampons and sanitary pads used each day during your period by placing a tally mark under the day next to the box representing the amount of bleeding noted each time you change your pads or tampon (see example at right) Record clots by indicating whether they are the size of a dime or a quarter coin in the small and in the large blood clot row under the relevant day.

Record any incidences of flooding

(accidents) by placing a tally mark in the menstrual accident row.

\section{Scoring the Chart:}

At the end of your period tabulate a "Total Score" by multiplying the total number of tallies in each row by the "Multiplying Factor" at the end of the row. Then sum the "Row Totals" to obtain the final "Total Score"

\section{Example:}

Ms. Smith in the first day of her period, she used 7 pads ( 5 lightly stained, 1 moderately and 1 heavy stained). She also used 1 moderately stained tampon and had 3 blood clots 1 small and 2 large. She also had one incidence of flooding.

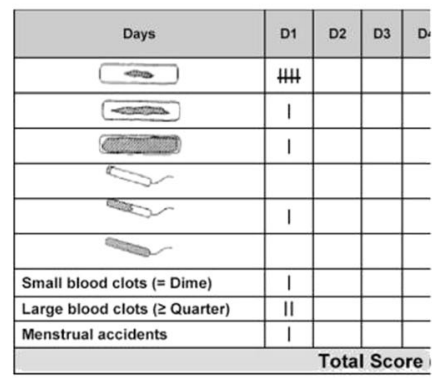

Fig. 1 Pictorial blood assessment chart [modified with permission from John Wiley and Sons (Figure 1 in 4)]

evaluate the diagnostic accuracy of PBLAC in evaluating MBL.

\section{Methods}

This systematic review was reported in accordance with the Meta-analysis of Observational Studies in Epidemiology recommendation and the Standards for Reporting of Diagnostic Accuracy initiatives and the guidelines for conducting systematic reviews of diagnostic studies [13, 14].

\section{Systematic search strategy and study selection}

A systematic search of MEDLINE, EMBASE, Cumulative Index to Nursing \& Allied Health Literature (CINAHL), Web of Science, and EBM Reviews-Cochrane Central Register of Controlled Trials from inception until September 30, 2014 was performed. The objective of the search was to identify all published reports on the evaluation of menstrual blood loss in humans. No language restriction was applied. In this search, terms referring to "menorrhagia," "menstrual blood loss evaluation," and "pictorial chart" were used. Only studies that compared PBLAC to alkaline hematin were included in the review. The search was designed and conducted with the help of an experienced librarian. In addition, the bibliographies of the retrieved articles and recent reviews were used to identify additional studies.

\section{Outcome of interest}

The primary outcome was the diagnostic accuracy of PBLAC compared to objective measurements of MBL. The intention was to pool the results of identified studies using metaanalysis.

PBLAC is a chart that works by recording a count for each type of sanitary pad used and its degree of soaking as depicted in a pictorial example along with the count and size of blood clots. Menstrual accidents are also captured in a separate row. A row score is calculated by multiplying total count of each row by the "Multiplying factor" at the end of each row. Then, a "total score" is calculated by adding the row totals (Fig. 1). On the other hand, objective measurements of MBL are conducted by several spectrophotometric and radioisotopic methods, which directly measure the amount of blood in sanitary products based on hemoglobin content (alkaline hematin).

\section{Data collection and evaluation of the quality of included studies}

A sheet was designed for data collection; it included the number of patients in each study and the number who had 
subjective complaints. MBL in excess of $80 \mathrm{~mL}$ was used as the cutoff for the objective definition of excessive menstrual blood loss. Data about the range or variation of estimated MBL in each study were also included. The requisite data were extracted from the text, tables, or figures. Evaluation of the included reports using the Standards for Reporting of Diagnostic Accuracy (STARD) guidelines was planned [15].

\section{Statistical analysis}

For evaluation of the diagnostic accuracy of PBLAC score, sensitivity, specificity, likelihood ratios of a positive and negative test (LR+ and $\mathrm{LR}^{-}$), diagnostic odds ratio (DOR), and area under the curve (AUC) for receiver operator characteristic (ROC) curve were calculated. Likelihood ratio is the probability of a given level of a test result for patients with the disease divided by the probability of that same result for patients without the disease. Likelihood ratio of a positive test $(\mathrm{LR}+)$ equals sensitivity/(1-specificity); while, LR of a negative test (LR-) equals ( $1-$ sensitivity)/specificity. Diagnostic odds ratio ranges from zero to infinity, with higher values indicating better discriminatory test performance. Area under the curve ranges from zero to one with better accuracy with values towards 1.0 [15]. Receiver operator characteristic plot was done for studies which evaluated the diagnostic accuracy of pictorial blood assessment chart compared to alkaline hematin using statistical software program Meta-DiSc version 1.1.1 (Ramón y Cajal Hospital, Madrid, Spain). No pooling of data was attempted given the wide heterogeneity and variations between the included studies in the method used and the cutoffs for defining excessive menstrual blood loss. Analysis was done using JMP version 9.0 (SAS Institute Inc, Cary, NC, USA).

\section{Findings}

Our systematic search identified 295 reports. After exclusions, seven studies that evaluated the accuracy of PBLAC compared to alkaline hematin (gold standard) in the detection of $\mathrm{MBL}>80 \mathrm{~mL}$ were included for analysis (Fig. 2). Evaluation of the quality of the included reports was performed (Table 1) $[4,5,8-12]$. Apart from blinding to reference and index tests, the parameters of quality of these studies seemed satisfactory.

A total of 1152 women represented the pooled population of the seven studies. Of these, women who experienced $\mathrm{MBL}>80 \mathrm{~mL}$ ranged from 12 to $61 \%$ (average $38.71 \%$ ). Five studies assigned " $100 \mathrm{~mL}$ " as a cutoff point for assessment of PBLAC score accuracy including the first study that was conducted by Higham. Other cutoff points $(50,80$, and $150 \mathrm{~mL}$ ) were used in individual studies. Sanitary products that were utilized in PBLAC score assessment are listed in Table 2.

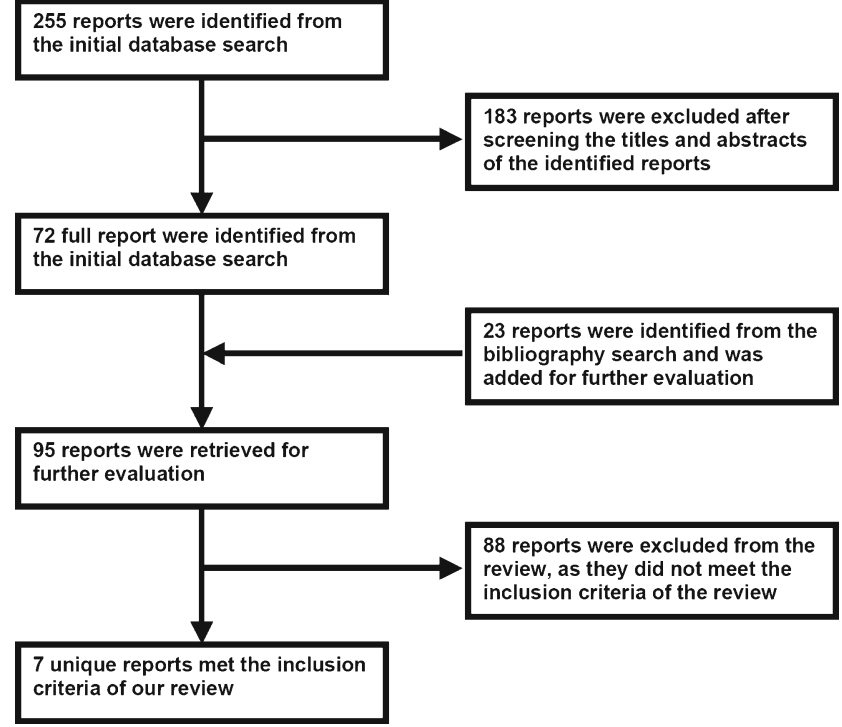

Fig. 2 Flow chart for study selection

The sensitivity of PBLAC ranged from 58 to $98 \%$, and the specificity from 7.5 to $97 \%$ with likelihood ratios (LR) for positive ranging from 1.1 to 7.8 and LR for negative tests ranging from 0.04 to 0.48 . The range of diagnostic odds ratio was from 2.6 to 86.9 (Table 2). However, the high level of variability among these studies precluded pooling of those estimates. Summary receiver operator characteristic (SROC) plot of the accuracy of PBLAC compared to alkaline hematin among recruited studies was illustrated in Fig. 3.

\section{Discussion}

MBL has been an issue of debate in both clinical practice and research work. Since PBLAC was introduced in the literature, validation of the chart has been a primary objective in several studies that were conducted in the last 25 years. In this systematic review, we described the diagnostic accuracy of PBLAC in these studies. Despite their heterogeneity, PBLAC seems to be a satisfactory alternative to objective methods that are difficult to implicate.

\section{Objective methods for assessment of MBL}

In the beginning of the twentieth century, several spectrophotometric and radioisotopic methods were developed to measure the amount of blood loss from sanitary products directly. The measurement of blood depended on either the measurement of hemoglobin content (e.g., acid hematin and alkaline hematin) or iron content (e.g., 
Table 1 Methodological quality evaluation with the quality assessment of diagnostic accuracy studies questionnaire

\begin{tabular}{|c|c|c|c|c|c|c|c|c|}
\hline \multirow[t]{2}{*}{ Quality } & \multirow[t]{2}{*}{ Question no. and primary characteristic } & \multicolumn{7}{|l|}{ Study } \\
\hline & & $\begin{array}{l}\text { Higham } \\
{[4]}\end{array}$ & $\begin{array}{l}\text { Janssen } \\
{[3]}\end{array}$ & $\begin{array}{l}\text { Deeny } \\
{[8]}\end{array}$ & $\begin{array}{l}\text { Barr } \\
{[9]}\end{array}$ & $\begin{array}{l}\text { Reid } \\
{[10]}\end{array}$ & $\begin{array}{l}\text { Wyatt } \\
{[11]}\end{array}$ & $\begin{array}{l}\text { Zakherah } \\
{[12]}\end{array}$ \\
\hline Generalizability & Q1: spectrum of patients & - & + & + & + & - & + & + \\
\hline \multirow[t]{5}{*}{ Clarity } & Q2: selection criteria & + & + & + & + & + & + & + \\
\hline & Q8: index test & + & + & + & + & + & + & + \\
\hline & Q9: reference test & + & + & + & + & + & + & + \\
\hline & Q13: uninterruptible/intermediate test results & + & + & + & + & - & + & + \\
\hline & Q14: withdrawals & + & + & + & + & + & + & + \\
\hline \multirow[t]{8}{*}{ Validity } & Q3: reference test & + & + & + & + & + & + & + \\
\hline & Q4: time between reference test and index test & + & + & + & + & + & + & + \\
\hline & Q5: verification using reference test & + & + & + & + & + & + & + \\
\hline & Q6: reference standard regardless of index test results & + & + & + & + & + & + & + \\
\hline & Q7: reference standard independent of the index test & + & + & + & + & + & + & + \\
\hline & Q10: blinding to reference test & - & - & - & - & - & - & - \\
\hline & Q11: blinding to index test & - & - & - & - & - & - & - \\
\hline & $\begin{array}{l}\text { Q12: same data available before interpretation of both index } \\
\text { and reference tests }\end{array}$ & + & + & + & + & + & + & + \\
\hline
\end{tabular}

The information is from Whiting et al. [13]. In the questionnaire, plus sign indicates "yes," minus sign indicates "no," and question mark indicates "unclear."

iron-labeled isotopes and chemical extraction of iron) [1, 2, 16-19]. Methods that depend on iron chemical extraction were limited by the low extraction rates and systematic underestimation of blood loss. The use of

Table 2 Diagnostic accuracy parameters of pictorial blood assessment chart (PBLAC) in the diagnoses for objective heavy menstrual bleeding (MBL $80 \mathrm{~mL}$ )

\begin{tabular}{|c|c|c|c|c|c|c|c|c|c|}
\hline Study & Number & $\begin{array}{l}\text { PBLAC } \\
\text { cutoff point } \\
\text { (in } \mathrm{mL} \text { ) }\end{array}$ & $\begin{array}{l}\text { Sanitary } \\
\text { product }\end{array}$ & $\begin{array}{l}\mathrm{MBL}>80 \mathrm{~mL} \\
(\%)\end{array}$ & $\begin{array}{l}\text { Sensitivity } \\
(\%)\end{array}$ & $\begin{array}{l}\text { Specificity } \\
(\%)\end{array}$ & $+\mathrm{LR}$ & $-\mathrm{LR}$ & DOR \\
\hline Higham et al. [4] & 122 & 100 & $\begin{array}{l}\text { Tampax Fems } \\
\text { super plus tampons } \\
\text { and Kotex Simplicity } \\
\text { size } 2 \text { towels }\end{array}$ & 50 & 86 & 89 & 7.8 & 0.16 & 50.1 \\
\hline Janssen et al. [3] & 288 & 100 & $\begin{array}{l}\text { Kotex Maxi Long Pads } \\
\text { (Kimberly Clark, Veenendaal, Holland), } \\
\text { Tampax super tampons } \\
\text { (Unicura, Zoetermeer, Holland) }\end{array}$ & 31 & 98 & 64 & 2.7 & 0.04 & 76.7 \\
\hline Deeny et al. [8] & 53 & 100 & $\begin{array}{l}\text { Women used their customary } \\
\text { sanitary material }\end{array}$ & 47 & 88 & 52 & 1.8 & 0.23 & 8.0 \\
\hline Barr et al. [9] & 281 & 50 & Sanitary wear not specified & 12 & 58 & 88 & 4.8 & 0.48 & 10.1 \\
\hline Reid et al. [10] & 103 & 100 & $\begin{array}{l}\text { Tampax super } \\
\text { (Tambrands, Havant, UK) } \\
\text { and Kotex Simplicity size } 2 \\
\text { (Kimberly Clark, Aylesford, Kent, UK) }\end{array}$ & 61 & 97 & 7.5 & 1.1 & 0.40 & 2.6 \\
\hline Wyatt et al. [11] & 108 & $80^{\mathrm{a}}$ & $\begin{array}{l}\text { Tampax regular, super, } \\
\text { or super plus and Kotex } \\
\text { Maxi super or Maxi } \\
\text { nighttime napkins }\end{array}$ & 16 & 86 & 88 & 7.2 & 0.16 & 45.3 \\
\hline \multirow[t]{2}{*}{ Zakherah et al. [12] } & 197 & 100 & \multirow{2}{*}{$\begin{array}{l}\text { Always Ultra, Proctor } \\
\text { \& Gamble, Cairo, Egypt }\end{array}$} & 54 & 99 & 39 & 1.6 & 0.02 & 86.9 \\
\hline & 197 & 150 & & 54 & 83 & 77 & 3.5 & 0.22 & 15.7 \\
\hline
\end{tabular}

$+L R$ likelihood ratio for a positive test, $L R-$ likelihood ratio for a negative test, $D O R$ diagnostic odds ratio

${ }^{a}$ In Wyatt report, the unit of score was an estimated milliliter unlike the original PBLAC by Higham, which included absolute values 


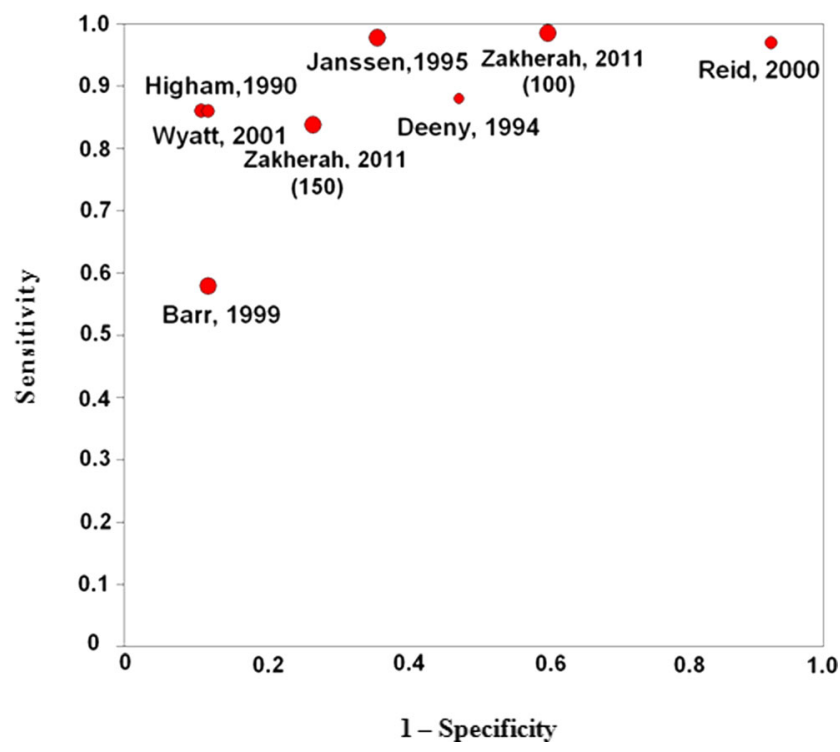

Fig. 3 Summary receiver operator characteristic (SROC) plot for studies which evaluated the diagnostic accuracy of pictorial blood assessment chart compared to alkaline hematin. Heterogeneity among study population and the use of various cutoff precluded pooling of the diagnostic accuracy measures in those studies

labeled isotopes conveyed some radiation exposure hazards and did not provide higher accuracy compared to spectrophotometric methods [20].

Because direct methods were sophisticated and were not suitable for implementation among general population, another approach was to indirectly calculate hemoglobin contents by weighing sanitary product before and after use [21]. Despite being simpler, the accuracy of this method is limited by the variability in the blood content of menstrual fluid which ranges between 30 and $50 \%$ of total menstrual fluid volume and which differs from day to day during menstrual period $[22,23]$. This method was refined by Fraser and colleagues in 2001; however, complexity of proper collection of the sanitary pads precluded its use in clinical and research settings [24].

In most objective methods, extensive efforts are needed by patients to collect their sanitary products along with the inconveniences and difficulties that often adversely impact the accuracy of collection of sanitary pads $[4,6]$. In addition, the measuring technique is lab intensive and impractical in the clinical settings [24]. Another concern is the inability to measure extraneous blood loss which can affect the total amount of MBL especially in cases of severe bleeding [25]. Finally, the recovered amounts of alkaline hematin are influenced by the variability of absorption of different sanitary products, a problem that could not be overcome unless a sanitary product is standardized or a reference is set for different sanitary products. All these factors precluded the use of extractionbased quantitative methods in clinical settings [26].

\section{Accuracy of pictorial blood assessment chart}

Given the inaccuracies of the subjective evaluation of MBL and the limitations of the objective methods that preclude their use in clinical practice, other methods have been developed. The most widely used is the PBLAC. While the score in the original PBLAC was not measured with actual blood loss, another chart was developed by Wyatt and colleague in 2001 [25]. The PBLAC is a practical method for quick evaluation of MBL in women that can be helpful in diagnosis and follow-up of treatment in women with heavy menstrual bleeding [27]. According to our review, although sensitivity, specificity, and LRs were not sufficient to support the accuracy of PBLAC in some studies, the diagnostic odds ratio generally ranged from 2.6 to 86.9 which is a satisfactory range for a good diagnostic test. However, the high level of variability in the accuracy of those studies precluded pooling of their estimates.

It remains one of the most questionable points related to the accuracy of PBLAC that there is no standard sanitary product for assessment of the score; products there were used to test and validate the score were not exactly those that are used nowadays. Accordingly, it has been a serious concern that modern superabsorbent polymer-containing sanitary products in comparison with old products, that were available when PBLAC was created, can confound current interpretation of the chart. Nevertheless, when women were encouraged to use the brands they commonly used, PBLAC was still significantly correlated to their perception of MBL with low intraindividual variation. Accordingly, standardization of sanitary product was not found to grossly impact the applicability of PBLAC [28]. In this review, it does not seem that the type of sanitary product contributes to the heterogeneity of results. SROC showed that studies that used the same products did not necessarily reveal comparable results and vice versa. However, Magnay et al. presented a new version of the traditional menstrual pictogram (the superabsorbent polymer-c or SAP-c version) which was designed to measure MBL on these widely used products (Always Ultra slim feminine towels "Proctor \& Gamble"). A validation study of this version yielded promising results when MBL was tested against alkaline hematin method and total menstrual fluid loss (MFL) against fluid weight $[29,30]$. Although initial results seem promising, implementation of this version among larger cohorts could help to recognize its feasibility, accuracy, and pitfalls and identify whether this version could be superior to the traditional PBLAC.

\section{Limitations}

The need to accurately document the amount of MBL in women as a prerequisite for offering treatment, which is the function of the PBLAC, has been questioned. Indeed, some 
authors have suggested that any amount of bleeding that adversely impacts a woman's quality of life requires intervention regardless of whether or not specific bleeding criteria are met [27]. Nevertheless, this pitfall is not specific and is associated with any objective estimation of MBL. Also, PBLAC seems to be the most reliable approach for researches that generally require a feasible quantitative method to evaluate and compare therapeutic approaches in women with HMB. It is also suitable for patient follow-up in concordance with clinical evaluation. In certain clinical circumstances when patient's symptomatology may be contributed to by a variety of clinical issues, objective assessment of MBL may be helpful to evaluate the rule of HMB. Another potential limitation in this review was the variability in alkaline hematin assessment methods and the lack of a standard to perform that method.

This review is also limited by the lack of meta-analysis for identification of pooled diagnostic accuracy of PBLAC compared to alkaline hematin for assessment of MBL due to the high level of heterogeneity in the methods and the estimated MBL. In addition, there is lack of information about the reliability of the test when used in the same patients repeatedly and if used after treatment. There is lack of consistency in reporting various endpoints and absence of many demographic characteristics and reliability measurements. This was mainly due to inclusion of many early reports, which had missing information, and the time gap did not help contacting authors. Finally, the diagnostic accuracy of PBLAC was limited in some studies; the range of positive LR was as low as 1.1 and negative LR was as high as 0.48 which indicates careful interpretation of current evidence. However, the diagnostic odds ratio was generally encouraging in most studies.

\section{Conclusions}

Despite highlighted limitations, studies that were conducted over 25 years retrieved satisfactory diagnostic outcomes that support the accuracy of PBLAC as a semi-objective method with acceptable diagnostic accuracy compared to objective measurement of MBL.

Conflict of interest The authors declare that they have no competing interest.

Informed consent This article does not contain any studies with human or animal subjects performed by the any of the authors.

Authors' contribution SAE carried out study search and selection and retrieval of data and participated in writing the manuscript. SAMS participated in writing the manuscript. AOF planned and supervised all these steps and revised the manuscript.

\section{References}

1. Hoppe-Seyler G, Brodersen A, Rudolph A (1904) About the loss of blood during menstruation. Z Physiol Chem 42:545-553

2. Barer AP, Fowler WM (1936) The blood loss during normal menstruation. Am J Obstet Gynecol 31:979-986

3. Janssen CA (2005) Menorrhagia: the $80 \mathrm{~mL}$ criterion and the usefulness in clinical practice. Am J Obstet Gynecol 192(6):2093

4. Higham JM, O’Brien PM, Shaw RW (1990) Assessment of menstrual blood loss using a pictorial chart. Br J Obstet Gynaecol 97(8): 734-739

5. Janssen CA, Scholten PC, Heintz AP (1995) A simple visual assessment technique to discriminate between menorrhagia and normal menstrual blood loss. Obstet Gynecol 85(6):977-982

6. Janssen CAH (1996) A simple visual assessment technique to discriminate between menorrhagia and normal menstrual blood loss. Eur J Obstet Gynecol Reprod Biol 70(1):21-22

7. American College of Obstetrics and Gynecology (2007) ACOG practice bulletin no. 81: endometrial ablation. Obstet Gynecol 109(5):1233-1248

8. Deeny M, Davis JA (1994) Assessment of menstrual blood loss in women referred for endometrial ablation. Eur J Obstet Gynecol Reprod Biol 57(3):179-180

9. Barr F, Brabin L, Agbaje O (1999) A pictorial chart for managing common menstrual disorders in Nigerian adolescents. Int $\mathrm{J}$ Gynaecol Obstet 66(1):51-53

10. Reid PC, Coker A, Coltart R (2000) Assessment of menstrual blood loss using a pictorial chart: a validation study. Br J Obstet Gynaecol 107(3):320-322

11. Wyatt KM, Dimmock PW, Hayes-Gill B, Crowe J, O'Brien PMS (2002) Menstrual symptometrics: a simple computer-aided method to quantify menstrual cycle disorders. Fertil Steril 78(1):96-101

12. Zakherah MS, Sayed GH, El-Nashar SA, Shaaban MM (2011) Pictorial blood loss assessment chart in the evaluation of heavy menstrual bleeding: diagnostic accuracy compared to alkaline hematin. Gynecol Obstet Investig 71(4):281-284

13. Whiting P, Rutjes AW, Dinnes J, Reitsma J, Bossuyt PM, Kleijnen J (2004) Development and validation of methods for assessing the quality of diagnostic accuracy studies. Health Technol Assess 8(25):iii, 1-234

14. Stroup DF, Berlin JA, Morton SC, Olkin I, Williamson GD, Rennie D et al (2000) Meta-analysis of observational studies in epidemiology: a proposal for reporting. Meta-analysis Of Observational Studies in Epidemiology (MOOSE) group. JAMA 283(15):20082012

15. Bossuyt PM, Reitsma JB, Bruns DE, Gatsonis CA, Glasziou PP, Irwig LM et al (2003) Towards complete and accurate reporting of studies of diagnostic accuracy: the STARD initiative. Ann Intern Med 138(1):40-44

16. Hallberg L, Nilsson L (1964) Determination of menstrual blood loss. Scand J Clin Lab Invest 16:244-248

17. Baldwin RM, Whalley PJ, Pritchard JA (1961) Measurements of menstrual blood loss. Am J Obstet Gynecol 81:739-742

18. Price DC, Forsyth EM, Cohn SH, Cronkite EP (1964) The study of menstrual and other blood loss, and consequent iron deficiency, by Fe59 whole-body counting. Can Med Assoc J 90:51-54

19. Tauxe WN (1962) Quantitation of menstrual blood loss: a radioactive method utilizing a counting dome. J Nucl Med 3:282-287

20. Hallberg L, Hogdahl AM, Nilsson L, Rybo G (1966) Menstrual blood loss - a population study. Variation at different ages and attempts to define normality. Acta Obstet Gynecol Scand 45(3):320 351

21. Pendergrass PB, Scott JN, Ream LJ (1984) A rapid, noninvasive method for evaluation of total menstrual loss. Gynecol Obstet Invest 17(4):174-178 
22. Fraser IS, McCarron G, Markham R, Resta T (1985) Blood and total fluid content of menstrual discharge. Obstet Gynecol 65(2): 194-198

23. Levin RJ, Wagner G (1986) Absorption of menstrual discharge by tampons inserted during menstruation: quantitative assessment of blood and total fluid content. Br J Obstet Gynaecol 93(7):765-772

24. Fraser IS, Warner P, Marantos PA (2001) Estimating menstrual blood loss in women with normal and excessive menstrual fluid volume. Obstet Gynecol 98(5 Pt 1):806-814

25. Wyatt KM, Dimmock PW, Walker TJ, O'Brien PM (2001) Determination of total menstrual blood loss. Fertil Steril 76(1): 125-131

26. O'Flynn N, Britten N (2000) Menorrhagia in general practicedisease or illness. Soc Sci Med 50(5):651-661
27. National Collaborating Center for Women's and Children Health. Heavy menstrual bleeding: Clinical Guidelines January, 2007. Welsh A, editor. London: RCOG Press; 2007. 152 p

28. Hald K, Lieng M (2014) Assessment of periodic blood loss: interindividual and intraindividual variations of pictorial blood loss assessment chart registrations. J Minim Invasive Gynecol 21(4):662668

29. Magnay JL, Nevatte TM, O’Brien S, Gerlinger C, Seitz C (2014) Validation of a new menstrual pictogram (superabsorbent polymerc version) for use with ultraslim towels that contain superabsorbent polymers. Fertil Steril 101(2):515-522

30. Magnay JL, Nevatte TM, Seitz C, O’Brien S (2013) A new menstrual pictogram for use with feminine products that contain superabsorbent polymers. Fertil Steril 100(6):1715-1721, e1-4 